\title{
Determining Benchmarks in Hearing Preservation Surgery for Vestibular Schwannoma
}

\author{
Michael B. Gluth ${ }^{1}$ John D. Day ${ }^{2}$ John L. Dornhoffer ${ }^{1}$ \\ ${ }^{1}$ Department of Otolaryngology-Head and Neck Surgery, University of \\ Address for correspondence and reprint requests Michael B. Gluth, \\ Arkansas for Medical Sciences, Little Rock, Arkansas, United States \\ M.D., 4301 W. Markham Street, \#543, Little Rock, AR 72205, United \\ 2 Department of Neurosurgery, University of Arkansas for Medical \\ States (e-mail: mbgluth@uams.edu). \\ Sciences, Little Rock, Arkansas, United States
}

J Neurol Surg B 2012;73:273-280.

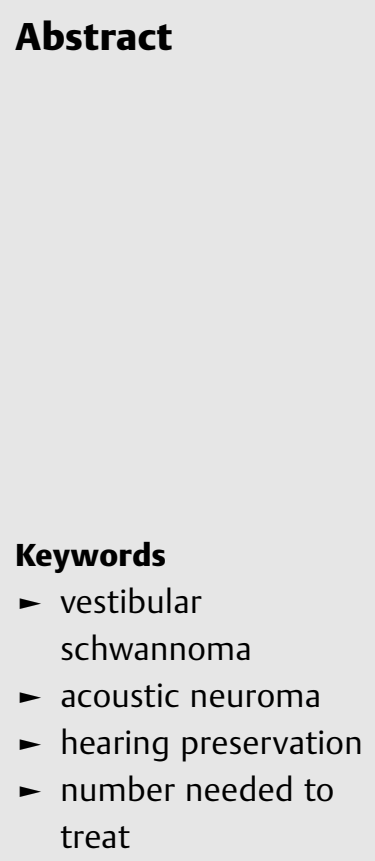

Objectives The objectives of this study were to determine minimal benchmarks of success in vestibular schwannoma hearing preservation surgery, wherein the likelihood of having preserved hearing in a single patient is at least as likely as having created a poor facial nerve outcome for a single patient.

Design This is a statistical analysis of published literature.

Setting Academic Tertiary Medical Center.

Main Outcome Measures Based on published natural history data, the number needed to treat (NNT) equation was used to calculate the minimally acceptable hearing preservation rates within various hearing classification schemes.

Results Given good facial nerve outcome rates of 85,90 , and $95 \%$, the corresponding hearing preservation rates at 4.7 years that are likely to preserve classes $A$ and $B$ hearing (American Academy of Otolaryngology-Head and Neck Surgery classification) in a single patient as to cause a poor facial nerve outcome are 70,65 , and $60 \%$, respectively. If surgery is limited exclusively to intracanalicular tumors, these rates drop to 62,57 , and $52 \%$, respectively. If the word recognition scoring classification is used, required hearing preservation rates are higher.

Conclusion It is possible to use the NNT equation alongside projected facial nerve outcomes to estimate benchmarks of minimally acceptable hearing preservation rates.

\section{Introduction}

Number needed to treat (NNT) is a statistical calculation used in epidemiology to help evaluate the efficiency and effectiveness of a given treatment modality in preventing one additional specified bad outcome. ${ }^{1}$ Defined as the inverse of the absolute risk reduction, NNT is generally expressed relative to the control in a clinical trial or the established natural history of a disease process over a set period of time. When controversy over a given intervention exists, NNT analysis can be useful in outlining the effectiveness of that treatment in straightforward, practical terms, and in establishing benchmarks for success. Microsurgical removal of vestibular schwannoma is one such instance of a controversial intervention that could benefit from NNT analysis. This is particularly so when a proactive approach is chosen, wherein surgical intervention is undertaken shortly after the point of diagnosis, without a period of observation to confirm active tumor growth.

The decision for proactive surgery is justified by the belief that loss of hearing associated with vestibular schwannoma may occur independent of observed tumor growth. ${ }^{2-4}$ received

August 1, 2011

accepted after revision

December 12, 2011

published online

May 17, 2012
Copyright $\odot 2012$ by Thieme Medical Publishers, Inc., 333 Seventh Avenue, New York, NY 10001, USA. Tel: +1(212) 584-4662.
DOI http://dx.doi.org/ 10.1055/s-0032-1312710. ISSN 2193-6331. 
Advocates of this management approach maintain that prompt surgical intervention may be the only opportunity to afford tumor removal while securing a preserved favorable hearing status ahead of any future loss secondary to tumor effects. For the two treatment options of observation versus microsurgery, NNT can be expressed over a given time period as:

$$
\begin{aligned}
\mathrm{NNT}= & 1 /(\text { probability of hearing loss with observation } \\
& - \text { probability of hearing loss with microsurgery })
\end{aligned}
$$

Ideally, NNT would be equal to a value of 1, which would indicate that microsurgical removal of the tumor would prevent hearing loss in every case; yet since hearing is not lost in every instance of observation, achieving this is not possible.

It is difficult to agree upon the theoretically acceptable number of patients needed to treat with microsurgery instead of observation to preserve hearing in a single patient with vestibular schwannoma. Consensus on this point is unlikely to come easily and may vary depending on factors such as complication rates and medical economic issues. However, based on the authors' experience over years of managing these tumors, we assert that a reasonable starting point lies within our impression that most patients would not choose unilateral hearing preservation at the price of poor facial nerve function. Although most reports portray favorable facial nerve outcomes in the vast majority of hearing preservation cases, ${ }^{5-7}$ poor outcomes do exist. Therefore, if the NNT for hearing preservation with surgery is equal to or greater than the corresponding poor facial nerve outcome rates (i.e., NNT $=10$, corresponding to a $90 \%$ good facial nerve outcome rate), proactive hearing preservation surgery may be difficult to justify.

In what follows, the authors attempt to take a practical yet in depth look at these points by applying the NNT equation to the available data pertaining to hearing preservation and facial nerve outcomes after resection of vestibular schwannoma. The purpose of this will be to suggest rough benchmarks that can be used as a tool for surgical teams to determine whether they believe proactive vestibular schwannoma microsurgery performed primarily on the basis of hearing preservation intent is justified at their institution depending on their own individualized outcomes.

\section{Materials and Methods}

Natural history data for hearing loss with observed vestibular schwannomas were obtained from Stangerup et $\mathrm{al}^{8}$ (all tumors, - Table 1) and Caye-Thomasen et $\mathrm{al}^{9}$ (intracanalicular only, - Table 2). These landmark reports published out of Denmark were derived from a large prospective comprehensive national health database in that country that has been maintained since 1976. They are arguably the source of "best evidence" available on the natural history of vestibular schwannoma. In addition, the Danish reports are particularly valuable in that hearing outcomes are presented in a table format for both the American Academy of Otolaryngology-Head and Neck
Surgery (AAO-HNS) classification ${ }^{10}$ and the word recognition scoring (WRS) classification, ${ }^{11}$ which is a modification of the AAO-HNS classification that depends entirely on WRS classification. In essence, this allows an "apples to apples" statistical comparison of surgical outcomes to the natural history according to a wide array of defined outcomes.

The natural history data was then extrapolated for the following changes between hearing class at diagnosis and hearing class at last evaluation: (AAO) $\mathrm{A}$ to $\mathrm{A}, \mathrm{A}$ to $\mathrm{A}$ and $\mathrm{B}, \mathrm{A}$ and $B$ to $A$ and $B, A B C$ to $A B C$; (WRS) 1 to 1,1 to 1 and 2,1 and 2 to 1 and $2,1,2$, and 3 to 1,2 , and 3 . We then used the NNT equation to calculate the associated percent of surgical patients with hearing preservation that would be required over a period of 4.6 to 4.7 years, which was the average follow-up for the Danish reports, to achieve an NNT value of $6.7,10$, and 20 , corresponding to good facial nerve outcome rates of 85 , 90 , and $95 \%$, respectively.

\section{Results}

Calculated "benchmarks" for hearing preservation surgery are shown in - Tables 3 and $\mathbf{4}$. Thus, one can use the benchmarks in -Table $\mathbf{3}$ for any tumor size based on a surgical team's definition of hearing preservation success and the surgeon's rate of good facial nerve outcome. Similarly, - Table 4 can be used if only intracanalicular tumors are considered proactive hearing preservation surgical candidates.

\section{Discussion}

The purpose of this effort is to explore the development of minimal benchmarks of success in vestibular schwannoma hearing preservation surgery. While the authors do not claim that the data presented here should stand as definite standards, the methodology outlined here can be used by individual surgical teams to assist in generating their own management strategies for vestibular schwannoma. It is important to note that the validity of this exercise is based on the authors' assertion that most patients would not trade a poor facial nerve outcome in exchange for unilateral hearing preservation; however, to actually prove that this assertion is valid, a cross-domain analysis including definition of tradeoff functions would be required. Because a complicated analysis such as this was not intended as part of this study, the authors' openly acknowledge that the key premise underlying this endeavor is still unproven.

Nevertheless, if the authors' assertion regarding the relative value of good facial nerve function to unilateral hearing preservation is accepted, a knowledge of disease natural history can be used alongside actual surgical outcomes to approximate minimal standards of hearing preservation success if one intends to justify the decision for surgical resection primarily as being to preserve hearing. It is important to note that the benchmarks shown in -Tables $\mathbf{3}$ and $\mathbf{4}$ represent minimum standards, wherein a case of hearing preservation has essentially been exchanged for a case of poor facial nerve outcome. Thus, it is doubtful that most surgical teams would feel the time and cost associated with such an "exchange" are 
Table 1 Natural History of Hearing with Observation in Patients with Vestibular Schwannoma, all Tumor Sizes, Followed for a Mean of 4.7 Years

\begin{tabular}{|l|l|l|l|l|}
\hline $\begin{array}{l}\text { Classification } \\
\text { Scheme }\end{array}$ & $\begin{array}{l}\text { Hearing Class at } \\
\text { Diagnosis Class at } \\
\text { Last Follow-Up }\end{array}$ & $\begin{array}{l}\text { Hearing Class at } \\
\text { Last Follow-Up }\end{array}$ & $\boldsymbol{n}$ & $\begin{array}{l}\text { \% with Same Class } \\
\text { Preserved at Last Follow-Up }\end{array}$ \\
\hline AAO & A & A & 178 & $51 \%$ \\
\hline & A & A and B & 178 & $81 \%$ \\
\hline & A and B & A and B & 455 & $55 \%$ \\
\hline WRS & A, B, and C & A, B, and C & 618 & $67 \%$ \\
\hline & 1 & 1 & 491 & $59 \%$ \\
\hline & 1 & 1 and 2 & 491 & $74 \%$ \\
\hline & 1 and 2 & 1 and 2 & 618 & $67 \%$ \\
\hline
\end{tabular}

Based on Stangerup et al. ${ }^{8}$

AAO, American Academy of Otolaryngology; WRS, word recognition scoring.

favorable, especially if the corresponding NNT is high. Significantly exceeding these benchmarks will be required in most instances to justify a proactive surgical approach based on hearing preservation intent.

An illustrative example of how this information can be used is as follows: if a surgical team defines success as preservation of preoperative classes A and B hearing postoperatively and asserts a good facial nerve outcome rate of $90 \%$ based on their experience with hearing preservation vestibular schwannoma surgery (no matter how they choose to define "good"), according to - Table 3 they will need to have successfully preserved hearing in $65 \%$ of cases at 4.7 years to have been just as likely to have prevented hearing loss in a single patient as they are to have caused a poor facial nerve outcome in a single patient. Thus, if they are not confident that they can exceed this $65 \%$ benchmark, hearing preservation surgery may not be recommended. Furthermore, since this is associated with a NNT of 10,10 surgeries must be performed in lieu of observation to affect this single instance of hearing preservation, but slightly fewer if the actual hearing preservation rate is better than $65 \%$.

A review of the relevant medical literature makes it apparent that these minimum benchmarks may be difficult to meet. This is shown in - Table 5, which summarizes published hearing outcome reports involving middle fossa microsurgery. ${ }^{6,11-23}$-Table 6 shows similar findings but is limited to reports of very small and/or intracanalicular tumors. $6,11,12,16,18,19,22-25$ In both of these tables, hearing outcomes according to various hearing preservation definitions were extrapolated from raw data present in each report. Similar comparisons could also be made to hearing preservation results with the retrosigmoid approach.

When reviewing - Tables 5 and $\mathbf{6}$, it is important to consider that these reports nearly all reflect immediate

Table 2 Natural History of Hearing with Observation in Patients with Vestibular Schwannoma, Intracanalicular Tumors Only, Followed for a Mean of 4.6 Years

\begin{tabular}{|l|l|l|l|l|}
\hline $\begin{array}{l}\text { Classification } \\
\text { Scheme }\end{array}$ & $\begin{array}{l}\text { Hearing Class } \\
\text { at Diagnosis Class at } \\
\text { Last Follow-Up }\end{array}$ & $\begin{array}{l}\text { Hearing Class at } \\
\text { Last Follow-Up }\end{array}$ & $\begin{array}{l}\text { \% with Same Class } \\
\text { Preserved at } \\
\text { Last Follow-Up }\end{array}$ \\
\hline AAO & A & A & 19 & $47 \%$ \\
\hline & A & A and B & n/a $a^{\mathrm{a}}$ & $\mathrm{n} / \mathrm{a}^{\mathrm{a}}$ \\
\hline & $\mathrm{A}$ and B & A and B & 45 & $47 \%$ \\
\hline & $\mathrm{A}, \mathrm{B}$, and C & $\mathrm{A}, \mathrm{B}$, and C & 65 & $68 \%$ \\
\hline WRS & 1 & 1 & 50 & $56 \%$ \\
\hline & 1 & 1 and 2 & $\mathrm{n} / \mathrm{a}^{\mathrm{a}}$ & $\mathrm{n} / \mathrm{a}^{\mathrm{a}}$ \\
\hline & 1 and 2 & 1 and 2 & 65 & $65 \%$ \\
\hline & 1,2 , and 3 & 1,2 , and 3 & 90 \\
\hline
\end{tabular}

Based on Caye-Thomasen et al. $^{9}$

${ }^{a}$ It was not possible to extrapolate these numbers for intracanalicular tumors due to the manner in which data were presented by Caye-Thomasen et al. ${ }^{9}$

AAO, American Academy of Otolaryngology; WRS, word recognition scoring. 
Table 3 Benchmarks for Minimally Acceptable Hearing Preservation Rates, All Tumors ${ }^{\mathrm{a}}$

\begin{tabular}{|c|c|c|c|c|}
\hline \multicolumn{2}{|c|}{ Definition of Hearing Preservation Success } & \multicolumn{3}{|c|}{$\begin{array}{l}\text { Projected Rate of Good Facial Nerve Outcomes } \\
\text { (Justified NNT Associated With Each Percentage) }\end{array}$} \\
\hline PreOp Hearing Class & PostOp Hearing Class & $85 \%(6.7)$ & $90 \%(10)$ & $95 \%(20)$ \\
\hline \multicolumn{5}{|l|}{ AAO } \\
\hline A & A & $66 \%$ & $61 \%$ & $56 \%$ \\
\hline A & $A$ and $B$ & $96 \%$ & $91 \%$ & $86 \%$ \\
\hline$A$ and $B$ & $A$ and $B$ & $70 \%$ & $65 \%$ & $60 \%$ \\
\hline$A, B$, and $C$ & $A, B$, and $C$ & $82 \%$ & $77 \%$ & $72 \%$ \\
\hline \multicolumn{5}{|l|}{ WRS } \\
\hline 1 & 1 & $74 \%$ & $69 \%$ & $64 \%$ \\
\hline 1 & 1 and 2 & $89 \%$ & $84 \%$ & $79 \%$ \\
\hline 1 and 2 & 1 and 2 & $82 \%$ & $77 \%$ & $72 \%$ \\
\hline 1,2 , and 3 & 1,2 , and 3 & $97 \%$ & $92 \%$ & $87 \%$ \\
\hline
\end{tabular}

${ }^{a}$ Surgical hearing preservation rates must endure up to 4.7 years to result in an equal likelihood of preventing hearing loss in one patient as causing a poor facial nerve outcome in one patient (based on natural history data by Stangerup et $\mathrm{al}^{8}$ ).

AAO, American Academy of Otolaryngology; NNT, number needed to treat; PostOp, postoperative; PreOp, preoperative; WRS, word recognition scoring.

hearing outcomes during the first year after surgery. Thus, they cannot be directly compared with - Tables $\mathbf{1}$ and $\mathbf{2}$, which are based on much longer average follow-up periods (4.7 and 4.6 years, respectively). Based on the limited data available, ${ }^{4,17,26}$ it appears that hearing that is preserved in the immediate postoperative period will persist at the same hearing class at 5 years postoperatively in roughly 70 to $90 \%$ of cases. Thus, with application of a 70 to $90 \% 5$-year hearing deterioration modifier, a hearing preservation rate somewhere between 72 and 93\% would likely be required under the example conditions outlined in the "Results" section to meet the minimum benchmark.

That said, skull base microsurgery is an ever-evolving field in which innovation may progressively improve hearing preservation outcomes. Indeed, Meyer et a ${ }^{11}$ reported that when analysis of results at the University of Iowa was limited only to very small tumors that had been removed since the advent of intraoperative direct near field eighth nerve compound action potential monitoring, hearing preservation outcomes improved substantially. Furthermore, improved

Table 4 Benchmarks for Minimally Acceptable Hearing Preservation Rates, Intracanalicular Tumors Onlya

\begin{tabular}{|c|c|c|c|c|}
\hline \multicolumn{2}{|c|}{ Definition of Hearing Preservation Success } & \multicolumn{3}{|c|}{$\begin{array}{l}\text { Projected Rate of Good Facial Nerve Outcomes } \\
\text { (Justified NNT Associated with Each Percentage) }\end{array}$} \\
\hline Preop Hearing Class & Postop Hearing Class & $85 \%(6.7)$ & $90 \%(10)$ & $95 \%(20)$ \\
\hline \multicolumn{5}{|l|}{$\mathrm{AAO}$} \\
\hline A & A & $62 \%$ & $57 \%$ & $52 \%$ \\
\hline A & $A$ and $B$ & $\mathrm{n} / \mathrm{a}^{\mathrm{b}}$ & $\mathrm{n} / \mathrm{a}^{\mathrm{b}}$ & $\mathrm{n} / \mathrm{a}^{\mathrm{b}}$ \\
\hline$A$ and $B$ & $A$ and $B$ & $62 \%$ & $57 \%$ & $52 \%$ \\
\hline$A, B$, and $C$ & $A, B$, and $C$ & $83 \%$ & $78 \%$ & $73 \%$ \\
\hline \multicolumn{5}{|l|}{ WRS } \\
\hline 1 & 1 & $71 \%$ & $66 \%$ & $61 \%$ \\
\hline 1 & 1 and 2 & $\mathrm{n} / \mathrm{a}^{\mathrm{b}}$ & $\mathrm{n} / \mathrm{a}^{\mathrm{b}}$ & $\mathrm{n} / \mathrm{a}^{\mathrm{b}}$ \\
\hline 1 and 2 & 1 and 2 & $80 \%$ & $75 \%$ & $70 \%$ \\
\hline 1,2 , and 3 & 1,2 , and 3 & $87 \%$ & $82 \%$ & $77 \%$ \\
\hline
\end{tabular}

${ }^{a}$ Surgical hearing preservation rates must endure up to 4.6 years to result in an equal likelihood of preventing hearing loss in one patient as causing a poor facial nerve outcome in one patient (based on natural history data by Caye-Thomasen et $\mathrm{al}^{9}$ ).

${ }^{b}$ Could not be calculated as it was not possible to extrapolate natural history numbers for intracanalicular tumors due to the manner in which data were presented by Caye-Thomasen et al. ${ }^{9}$

AAO, American Academy of Otolaryngology; n/a, not applicable; NNT, number needed to treat; PostOp, postoperative; PreOp, preoperative; WRS, word recognition scoring. 
Vestibular Schwannoma Hearing Preservation Benchmarks Gluth et al. 277

Table 5 Middle Fossa Approach Hearing Preservation Results-All Tumors

\begin{tabular}{|c|c|c|c|}
\hline Location, Publication, and Source of Data & Hearing Outcomes & Number of Cases & Percent with Specified Outcome \\
\hline $\begin{array}{l}\text { lowa City, USA } \\
\text { Meyer et al, } 2006 \\
\text { Table } 3\end{array}$ & $\begin{array}{l}\text { AAO } A->A \\
\text { AAO A }->A B \\
\text { AAO AB }->A B \\
\text { AAO ABC }->A B C \\
\text { WRS } 1->1 \\
\text { WRS } 1->12 \\
\text { WRS } 123->123\end{array}$ & $\begin{array}{l}98 \\
98 \\
124 \\
132 \\
113 \\
113 \\
156\end{array}$ & $\begin{array}{l}38 \% \\
57 \% \\
57 \% \\
57 \% \\
50 \% \\
56 \% \\
59 \%\end{array}$ \\
\hline $\begin{array}{l}\text { Los Angeles, USA } \\
\text { Brackmann et al, } 2000 \\
\text { Table } 3\end{array}$ & $\begin{array}{l}A A O A->A \\
A A O A->A B \\
A A O A B->A B\end{array}$ & $\begin{array}{l}199 \\
199 \\
300\end{array}$ & $\begin{array}{l}51 \% \\
70 \% \\
63 \%\end{array}$ \\
\hline $\begin{array}{l}\text { Ann Arbor, USA } \\
\text { Arts et al, } 2006 \\
\text { Table } 1\end{array}$ & $\begin{array}{l}A A O A->A \\
A A O A->A B \\
A A O A B->A B \\
A A O A B C->A B C\end{array}$ & $\begin{array}{l}34 \\
34 \\
62 \\
65\end{array}$ & $\begin{array}{l}62 \% \\
79 \% \\
73 \% \\
77 \%\end{array}$ \\
\hline $\begin{array}{l}\text { Boston, USA } \\
\text { Staecker et al, } 2000 \\
\text { Tables } 1 \text { and } 2\end{array}$ & $\begin{array}{l}\text { AAO A- }>A \\
\text { AAO A- }>A B \\
\text { AAO AB- }>A B \\
\text { WRS } 1->1 \\
\text { WRS1- }>12 \\
\text { WRS123- }>123\end{array}$ & $\begin{array}{l}12 \\
12 \\
17 \\
17 \\
17 \\
17\end{array}$ & $\begin{array}{l}42 \% \\
58 \% \\
65 \% \\
53 \% \\
71 \% \\
82 \%\end{array}$ \\
\hline $\begin{array}{l}\text { Pittsburgh, USA } \\
\text { Arriaga et al, } 1997 \\
\text { Table } 1\end{array}$ & $\begin{array}{l}\text { AAO } A->A \\
\text { AAO } A->A B \\
\text { AAO AB }->A B \\
\text { AAO ABC }>\text { ABC } \\
\text { WRS } 1->1 \\
\text { WRS1- }>12 \\
\text { WRS123- }>123\end{array}$ & $\begin{array}{l}23 \\
23 \\
30 \\
32 \\
27 \\
27 \\
34\end{array}$ & $\begin{array}{l}61 \% \\
70 \% \\
73 \% \\
72 \% \\
74 \% \\
74 \% \\
79 \% \\
\end{array}$ \\
\hline $\begin{array}{l}\text { Verona, Italy } \\
\text { Colletti et al, } 2003 \\
\text { Text }\end{array}$ & $\mathrm{AAO} A B->A B$ & 35 & $51 \%$ \\
\hline $\begin{array}{l}\text { Erlangen, Germany } \\
\text { Gjuric et al, } 2001 \\
\text { Tables 4-7 }\end{array}$ & $\begin{array}{l}A A O A->A \\
A A O A->A B \\
A A O A B->A B \\
A A O A B C->A B C\end{array}$ & $\begin{array}{l}277 \\
277 \\
423 \\
514\end{array}$ & $\begin{array}{l}37 \% \\
51 \% \\
44 \% \\
49 \% \\
\end{array}$ \\
\hline $\begin{array}{l}\text { San Francisco, USA } \\
\text { Satar et al, } 2002 \\
\text { Table } 3\end{array}$ & $\begin{array}{l}A A O A->A \\
A A O A->A B \\
A A O A B->A B \\
A A O A B C->A B C\end{array}$ & $\begin{array}{l}64 \\
64 \\
135 \\
143\end{array}$ & $\begin{array}{l}44 \% \\
59 \% \\
53 \% \\
63 \%\end{array}$ \\
\hline $\begin{array}{l}\text { Tokyo, Japan } \\
\text { Kanzaki et al, } 2001 \\
\text { Tables } 1-3\end{array}$ & $\begin{array}{l}A A O A->A \\
A A O A->A B \\
A A O A B->A B\end{array}$ & $\begin{array}{l}71 \\
71 \\
127\end{array}$ & $\begin{array}{l}37 \% \\
48 \% \\
38 \%\end{array}$ \\
\hline $\begin{array}{l}\text { Ehime, Japan } \\
\text { Kumon et al, } 2000 \\
\text { Tables } 1-3\end{array}$ & $\begin{array}{l}\text { AAO } A->A \\
\text { AAO A }->A B \\
\text { AAO AB }->A B \\
\text { AAO ABC }->A B C \\
\text { WRS } 1->1 \\
\text { WRS1- }>12 \\
\text { WRS123- }>123\end{array}$ & $\begin{array}{l}13 \\
13 \\
26 \\
32 \\
31 \\
31 \\
36 \\
\end{array}$ & $\begin{array}{l}46 \% \\
54 \% \\
62 \% \\
78 \% \\
77 \% \\
81 \% \\
81 \% \\
\end{array}$ \\
\hline $\begin{array}{l}\text { Wurzburg, Germany } \\
\text { Dornhoffer et al, } 1995 \\
\text { Table } 3\end{array}$ & $A B->A B$ & 93 & $58 \%$ \\
\hline $\begin{array}{l}\text { Minneapolis, USA } \\
\text { Hilton et al, } 2011 \\
\text { Table } 1\end{array}$ & $\begin{array}{l}A->A \\
A->A B \\
A B->A B\end{array}$ & $\begin{array}{l}64 \\
64 \\
78\end{array}$ & $\begin{array}{l}34 \% \\
67 \% \\
65 \%\end{array}$ \\
\hline $\begin{array}{l}\text { New York, USA } \\
\text { Phillips et al, } 2010 \\
\text { Text }\end{array}$ & $A B->A B$ & 17 & $71 \%$ \\
\hline $\begin{array}{l}\text { Rome, Italy } \\
\text { Sanna et al, } 2004 \\
\text { Table } 6\end{array}$ & $\begin{array}{l}A A O A->A \\
A A O A B->A B \\
A A O A B C->A B C\end{array}$ & $\begin{array}{l}35 \\
58 \\
59\end{array}$ & $\begin{array}{l}11 \% \\
33 \% \\
49 \%\end{array}$ \\
\hline
\end{tabular}

AAO, American Academy of Otolaryngology; WRS, word recognition scoring. 
Vestibular Schwannoma Hearing Preservation Benchmarks Gluth et al.

Table 6 Middle Fossa Approach Hearing Preservation Results-Small $(<1 \mathrm{~cm})$ or Intracanalicular Tumors Only

\begin{tabular}{|c|c|c|c|}
\hline $\begin{array}{l}\text { Location, Publication, Tumor Size, } \\
\text { and Source of Data }\end{array}$ & Hearing Outcomes & Number of Cases & $\begin{array}{l}\text { Percent with } \\
\text { Specified Outcome }\end{array}$ \\
\hline $\begin{array}{l}\text { lowa City, USA } \\
\text { Meyer et al, } 2006 \\
\text { a } \leq 10 \mathrm{~mm} \text { tumors } \\
\text { Table } 4\end{array}$ & $\begin{array}{l}\text { AAO } A->A \\
\text { AAO A }->A B \\
\text { AAO AB }->A B \\
\text { AAO ABC }->A B C \\
\text { WRS } 12->12 \\
\text { WRS } 1->1 \\
\text { WRS } 1->12 \\
\text { WRS } 123->123\end{array}$ & $\begin{array}{l}57 \\
57 \\
73 \\
77 \\
77 \\
66 \\
66 \\
89\end{array}$ & $\begin{array}{l}49 \% \\
65 \% \\
66 \% \\
66 \% \\
66 \% \\
59 \% \\
65 \% \\
72 \% \\
\end{array}$ \\
\hline $\begin{array}{l}\text { Verona, Italy } \\
\text { Colletti et al, } 2005 \\
\text { alntracanalicular tumors } \\
\text { Table } 6\end{array}$ & $A A O A B->A B$ & 35 & $51 \%$ \\
\hline $\begin{array}{l}\text { Pittsburgh, USA } \\
\text { Arriaga et al, } 1997 \\
\text { a } \leq 10 \mathrm{~mm} \text { tumors } \\
\text { Table } 1\end{array}$ & $\begin{array}{l}\text { AAO A }->A \\
\text { AAO A }->A \\
\text { AAO A }->A B \\
\text { AAO AB }->A B \\
\text { WRS } 1->1 \\
\text { WRS1- }>12 \\
\text { WRS123- > } 123\end{array}$ & $\begin{array}{l}20 \\
20 \\
20 \\
27 \\
24 \\
24 \\
30\end{array}$ & $\begin{array}{l}60 \% \\
60 \% \\
70 \% \\
75 \% \\
75 \% \\
75 \% \\
80 \% \\
\end{array}$ \\
\hline $\begin{array}{l}\text { San Francisco, USA } \\
\text { Satar et al, } 2002 \\
\text { alntracanalicular } \\
\text { Table } 3\end{array}$ & $\begin{array}{l}A A O A->A \\
A A O A->A B \\
A A O A B->A B \\
A A O A B C->A B C\end{array}$ & $\begin{array}{l}26 \\
26 \\
53 \\
57\end{array}$ & $\begin{array}{l}50 \% \\
69 \% \\
62 \% \\
70 \% \\
\end{array}$ \\
\hline $\begin{array}{l}\text { Boston, USA } \\
\text { Staecker et al, } 2000 \\
\text { antracanalicular } \\
\text { Table } 1\end{array}$ & $\begin{array}{l}\text { AAO A- }>A \\
\text { AAO A- }>A B \\
\text { AAO AB- }>A B \\
\text { WRS } 1->1 \\
\text { WRS1- }>12 \\
\text { WRS123- }>123\end{array}$ & $\begin{array}{l}11 \\
11 \\
13 \\
13 \\
13 \\
13\end{array}$ & $\begin{array}{l}45 \% \\
55 \% \\
62 \% \\
54 \% \\
69 \% \\
85 \% \\
\end{array}$ \\
\hline $\begin{array}{l}\text { Ann Arbor, USA } \\
\text { Arts et al, } 2006 \\
{ }^{a} 10 \mathrm{~mm} \text { or less } \\
\text { Appendix } 1\end{array}$ & $\begin{array}{l}\text { AAO A }->A \\
\text { AAO A }-A B \\
\text { AAO AB }->A B \\
\text { WRS } 1->1 \\
\text { WRS1- }>12 \\
\text { WRS123- > } 123\end{array}$ & $\begin{array}{l}21 \\
21 \\
42 \\
40 \\
40 \\
48\end{array}$ & \begin{tabular}{l|}
$71 \%$ \\
$86 \%$ \\
$79 \%$ \\
$80 \%$ \\
$80 \%$ \\
$81 \%$ \\
\end{tabular} \\
\hline $\begin{array}{l}\text { Raleigh, USA } \\
\text { Sameshima et al, } 2010 \\
{ }^{a} \text { Maximum } 3 \mathrm{~mm} \\
\text { extrameatal extent } \\
\text { Table } 2\end{array}$ & $\begin{array}{l}\text { AAO } A->A \\
A A O A->A B \\
A A O A B->A B\end{array}$ & $\begin{array}{l}27 \\
27 \\
43\end{array}$ & $\begin{array}{l}59 \% \\
85 \% \\
77 \%\end{array}$ \\
\hline $\begin{array}{l}\text { Tokyo, Japan } \\
\text { Kanzaki et al, } 2001 \\
\text { antracanalicular Table } 1\end{array}$ & $\begin{array}{l}A A O A->A \\
A A O A->A B \\
A A O A B->A B\end{array}$ & $\begin{array}{l}36 \\
36 \\
56\end{array}$ & $\begin{array}{l}50 \% \\
56 \% \\
54 \%\end{array}$ \\
\hline $\begin{array}{l}\text { Ehime, Japan } \\
\text { Kumon et al, } 2000 \\
\text { antracanalicular } \\
\text { Table } 1\end{array}$ & $\begin{array}{l}A A O A->A \\
\text { AAO A }->A B \\
\text { AAO AB }->A B \\
\text { AAO ABC }->A B C \\
\text { WRS } 1->1 \\
\text { WRS1- }>12 \\
\text { WRS123- }>123\end{array}$ & $\begin{array}{l}6 \\
6 \\
13 \\
15 \\
15 \\
15 \\
15\end{array}$ & $\begin{array}{l}67 \% \\
83 \% \\
69 \% \\
93 \% \\
87 \% \\
93 \% \\
93 \% \\
\end{array}$ \\
\hline $\begin{array}{l}\text { Erlangen, Germany } \\
\text { Gjuric et al, } 2001 \\
\text { alntracanalicular } \\
\text { Table } 4\end{array}$ & $\begin{array}{l}A A O A->A \\
A A O A->A B \\
A A O A B->A B \\
A A O A B C->A B C\end{array}$ & $\begin{array}{l}76 \\
76 \\
114 \\
129\end{array}$ & $\begin{array}{l}50 \% \\
68 \% \\
61 \% \\
67 \%\end{array}$ \\
\hline
\end{tabular}

AAO, American Academy of Otolaryngology; WRS, word recognition scoring.

aTumor size parameter of reported subjects. 
selection of patients that are ideal for hearing preservation surgery, such as those with a relatively medial-based tumor as indicated by the presence of a lateral fundal fluid signal on magnetic resonance imaging, may improve outcomes as well. Thus, the body of the reported literature may not always reflect modern outcomes.

It should be stressed that the statistical analysis undertaken in this report pertains especially to the issue of proactive hearing preservation surgery, where the intent to prevent hearing loss is the impetus for choosing surgery over observation. However, when treatment is indicated due to progressive tumor growth and serviceable hearing is still present, attempting to preserve hearing during tumor removal is almost always advised at the authors' institution when conditions are reasonable (size and degree of lateral extension), especially when contralateral hearing is poor.

One interesting point evident from our data are that if the WRS classification is to be used, as has been advocated by some surgeons, the associated benchmarks for success based on the NNT equation and facial nerve outcomes are higher. In other words, even though the WRS classification may render more patients candidates for hearing preservation surgery, it also requires better outcome standards to justify such an approach. In contrast to the example provided in our "Results" section, preservation of preoperative WRS classes 1 and 2 postoperatively with a similar $90 \%$ rate of good facial nerve outcomes will define $77 \%$ hearing preservation as a minimal benchmark at 4.7 years, as opposed to $65 \%$ with preservation of the AAO A and B classes.

Although we have chosen to use the rate of good facial nerve outcome as part of our analysis, the NNT equation can also be applied to other useful parameters. For instance, when a surgeon's established rate of hearing preservation is only slightly better than the natural history with observation, the NNT value will likely be quite high ( $>20$ cases required to prevent a single case of hearing loss). In an era of rising scrutiny of medical expenditures, such figures can be evaluated to determine the cost-effectiveness (or lack thereof) of proactive surgery.

Stereotactic radiosurgery has not been addressed in this analysis. Whether or not radiosurgery has the potential to improve the chances of hearing preservation compared with the natural history is controversial. ${ }^{27,28}$ When attempting to determine an acceptable NNT value for stereotactic radiosurgery, the self-evident endpoint of not exceeding the rate of a poor facial nerve outcome will result in much lower hearing preservation benchmarks due to the extremely low incidence of facial nerve weakness after radiosurgery. Additionally, the lower cost of stereotactic radiosurgery compared with microsurgery is likely to render hospitals more tolerant of a high NNT value.

This study relies exclusively on two recent reports from Denmark $^{8,9}$ that are based on an extensive national database of patients with vestibular schwannoma that has been maintained for over three decades. The report by Stangerup et $\mathrm{al}^{8}$ has the advantage of including large numbers of subjects with all tumor sizes. This is useful as most surgical outcome reports do not exclusively involve very small ( $<10 \mathrm{~mm}$ ) and/or intra- canalicular tumors, which is the focus of the more limited Caye-Thomasen et al report. ${ }^{9}$ However, differences in outcomes reported per hearing class between the Stangerup et al and Caye-Thomasen et al reports do not appear to be glaringly different. Although other non-Danish publications involving the natural history of hearing with observation of vestibular schwannoma do exist, ${ }^{29-32}$ most fail to match the comprehensiveness, detail, and prospective study design of the Danish reports. Thus for our purposes, we believe limiting our data on natural history to these two landmark articles is quite reasonable.

In summary, by using data on the natural history of hearing that has been obtained by vestibular schwannoma observation, the NNT equation can be applied alongside projected facial nerve outcomes to approximate benchmarks for minimally acceptable hearing preservation rates, under the premise that surgical resection should afford a likelihood of successful hearing preservation that is at least on par with the chance of poor facial nerve outcome.

\section{References}

1 Cook RJ, Sackett DL. The number needed to treat: a clinically useful measure of treatment effect. BMJ 1995;310(6977):452-454

2 Tschudi DC, Linder TE, Fisch U. Conservative management of unilateral acoustic neuromas. Am J Otol 2000;21(5):722-728

3 Raut VV, Walsh RM, Bath AP, et al. Conservative management of vestibular schwannomas - second review of a prospective longitudinal study. Clin Otolaryngol Allied Sci 2004;29(5): 505-514

4 Woodson EA, Dempewolf RD, Gubbels SP, et al. Long-term hearing preservation after microsurgical excision of vestibular schwannoma. Otol Neurotol 2010;31(7):1144-1152

5 Arriaga MA, Chen DA. Facial function in hearing preservation acoustic neuroma surgery. Arch Otolaryngol Head Neck Surg 2001;127(5):543-546

6 Arts HA, Telian SA, El-Kashlan H, Thompson BG. Hearing preservation and facial nerve outcomes in vestibular schwannoma surgery: results using the middle cranial fossa approach. Otol Neurotol 2006;27(2):234-241

7 Harsha WJ, Backous DD. Counseling patients on surgical options for treating acoustic neuroma. Otolaryngol Clin North Am 2005;38 (4):643-652

8 Stangerup SE, Thomsen J, Tos M, Cayé-Thomasen P. Long-term hearing preservation in vestibular schwannoma. Otol Neurotol 2010;31(2):271-275

9 Caye-Thomasen P, Dethloff T, Hansen S, Stangerup SE, Thomsen J. Hearing in patients with intracanalicular vestibular schwannomas. Audiol Neurootol 2007;12(1):1-12

10 American Academy of Otolaryngology-Head \& Neck Surgery. Committee on Hearing and Equilibrium guidelines for the evaluation of hearing preservation in acoustic neuroma (vestibular schwannoma). American Academy of Otolaryngology-Head and Neck Surgery Foundation, INC. Otolaryngol Head Neck Surg 1995;113(3):179-180

11 Meyer TA, Canty PA, Wilkinson EP, Hansen MR, Rubinstein JT, Gantz BJ. Small acoustic neuromas: surgical outcomes versus observation or radiation. Otol Neurotol 2006;27(3):380-392

12 Arriaga MA, Chen DA, Fukushima T. Individualizing hearing preservation in acoustic neuroma surgery. Laryngoscope 1997;107(8): 1043-1047

13 Brackmann DE, Owens RM, Friedman RA, et al. Prognostic factors for hearing preservation in vestibular schwannoma surgery. Am J Otol 2000;21(3):417-424 
14 Colletti V, Fiorino F. Middle fossa versus retrosigmoid-transmeatal approach in vestibular schwannoma surgery: a prospective study. Otol Neurotol 2003;24(6):927-934

15 Dornhoffer JL, Helms J, Hoehmann DH. Hearing preservation in acoustic tumor surgery: results and prognostic factors. Laryngoscope 1995;105(2):184-187

16 Gjurić M, Wigand ME, Wolf SR. Enlarged middle fossa vestibular schwannoma surgery: experience with 735 cases. Otol Neurotol 2001;22(2):223-230, discussion 230-231

17 Hilton CW, Haines SJ, Agrawal A, Levine SC. Late failure rate of hearing preservation after middle fossa approach for resection of vestibular schwannoma. Otol Neurotol 2011;32(1):132-135

18 Kanzaki J, Inoue Y, Ogawa K. The learning curve in post-operative hearing results in vestibular schwannoma surgery. Auris Nasus Larynx 2001;28(3):209-213

19 Kumon Y, Sakaki S, Kohno K, et al. Selection of surgical approaches for small acoustic neurinomas. Surg Neurol 2000;53(1):52-59, discussion 59-60

20 Phillips DJ, Kobylarz EJ, De Peralta ET, Stieg PE, Selesnick SH. Predictive factors of hearing preservation after surgical resection of small vestibular schwannomas. Otol Neurotol 2010;31(9): 1463-1468

21 Sanna M, Khrais T, Russo A, Piccirillo E, Augurio A. Hearing preservation surgery in vestibular schwannoma: the hidden truth. Ann Otol Rhinol Laryngol 2004;113(2):156-163

22 Satar B, Jackler RK, Oghalai J, Pitts LH, Yates PD. Risk-benefit analysis of using the middle fossa approach for acoustic neuromas with $>10 \mathrm{~mm}$ cerebellopontine angle component. Laryngoscope 2002;112(8 Pt 1):1500-1506

23 Staecker H, Nadol JB Jr, Ojeman R, Ronner S, McKenna MJ. Hearing preservation in acoustic neuroma surgery: middle fossa versus retrosigmoid approach. Am J Otol 2000;21(3):399-404
24 Colletti V, Fiorino F. Is the middle fossa approach the treatment of choice for intracanalicular vestibular schwannoma? Otolaryngol Head Neck Surg 2005;132(3):459-466

25 Sameshima T, Fukushima T, McElveen JT Jr, Friedman AH. Critical assessment of operative approaches for hearing preservation in small acoustic neuroma surgery: retrosigmoid vs middle fossa approach. Neurosurgery 2010;67(3):640-644, discussion 644-645

26 Friedman RA, Kesser B, Brackmann DE, Fisher LM, Slattery WH, Hitselberger WE. Long-term hearing preservation after middle fossa removal of vestibular schwannoma. Otolaryngol Head Neck Surg 2003;129(6):660-665

27 Niranjan A, Mathieu D, Flickinger JC, Kondziolka D, Lunsford LD. Hearing preservation after intracanalicular vestibular schwannoma radiosurgery. Neurosurgery 2008;63(6):1054-1062, discussion 1062-1063

28 Pollock BE, Driscoll CL, Foote RL, et al. Patient outcomes after vestibular schwannoma management: a prospective comparison of microsurgical resection and stereotactic radiosurgery. Neurosurgery 2006;59(1):77-85, discussion 77-85

29 Smouha EE, Yoo M, Mohr K, Davis RP. Conservative management of acoustic neuroma: a meta-analysis and proposed treatment algorithm. Laryngoscope 2005;115(3):450-454

30 Suryanarayanan R, Ramsden RT, Saeed SR, et al. Vestibular schwannoma: role of conservative management. J Laryngol Otol 2010;124(3):251-257

31 Walsh RM, Bath AP, Bance ML, Keller A, Rutka JA. Consequences to hearing during the conservative management of vestibular schwannomas. Laryngoscope 2000;110(2 Pt 1):250-255

32 Sughrue ME, Yang I, Aranda D, et al. The natural history of untreated sporadic vestibular schwannomas: a comprehensive review of hearing outcomes. J Neurosurg 2010;112(1):163-167 